How to cite

Mustafa, C. M., Radzi, M. N. M., Masnan, A. H., Bacotang, J., Isa, M. Z., Osman, Z., \& Alias, A. (2019). Teachers' practices in the acquisition of English by Asian Immigrant English language learners. Malaysian Journal of Learning and Instruction, 16(1), 207-232.

\title{
TEACHER PRACTICES IN THE ACQUISITION OF ENGLISH AMONG ASIAN IMMIGRANT ENGLISH LANGUAGE LEARNERS
}

\author{
${ }^{1}$ Mazlina Che Mustafa, Nor Mashitah Md. Radzi, Abdul Halim \\ Masnan, Juppri Bacotang, Zainiah Mohamed Isa, Zaharah \\ Osman \& Azila Alias \\ Department of Early Childhood Education \\ Faculty of Human Development \\ Universiti Pendidikan Sultan Idris
}

${ }^{I}$ Corresponding author: mazlina.cm@fppm.upsi.edu.my

Received: 24 May 2018 Revised: 29 October 2018 Accepted: 18 December 2018

\begin{abstract}
Purpose - The increase in the enrolments of immigrant children in New Zealand seems to have posed great challenges to early childhood education services when it comes to developing the children's English language acquisition. This qualitative case study explored how New Zealand early childhood teachers develop the English language acquisition of Asian immigrant English language learners (ELLs). The theoretical framework of this research drew on a range of sociocultural perspectives, including sociocultural adaptation and acculturation strategies.

Methodology - The main participants of this study were seven early childhood teachers and six Asian immigrant ELLs from two early childhood centres. Data on the teachers were collected through observations and semi-structured interviews. For each centre, observations were carried out over a six week period which enabled
\end{abstract}


a series of snapshots of how the teachers developed the English language acquisition of the ELLs.

Findings - Making interactions comprehensible for the ELLs is one of the main strategies used by the teachers in developing the acquisition of English language by the ELLs. In the process of teaching the English language to the ELLs, most of the teachers were observed to use certain strategies in making interactions comprehensible for them. The teachers highlighted the strategies and modifications they made in order to make their interactions comprehensible for the ELLs. During the interview, it was clearly seen that with better proficiency in the English language, the communication between the ELLs and their teachers improved. Therefore, the sociocultural adaptation process takes place in a smooth manner for both the ELLs and the teachers.

Significance-The central significance of the finding is that through the exploration of New Zealand early childhood teachers' beliefs and practices, important insights are offered which lead to the improvement of educational practices in early childhood settings for immigrant children in relation to English acquisition. While some of the teachers' beliefs and practices may have facilitative or positive effects on English acquisition, others may bring debilitative or harmful effects.

The findings also add to the existing body of knowledge on teachers' beliefs and practices in developing English acquisition among the ELLs, particularly Asian children. In the New Zealand early childhood education context, the study provides a platform on how early childhood teachers in New Zealand could develop English acquisition among Asian immigrant ELLs, while valuing and understanding children's cultural backgrounds.

Keywords: Early language learners, early childhood, Asian learners, second language acquisition, sociocultural theories.

\section{INTRODUCTION}

Little advancements in research have been made about how early childhood teachers develop English acquisition among Asian immigrant children despite the growing number of Asian immigrant 
children enrolled in New Zealand early childhood education centres. As of 1 July 2010, Asian enrolments $(13,181)$ accounted for $7.0 \%$ of the total enrolments $(188,924)$ in licensed early childhood services, only second to European/Pākehā (63.1\%) and Māori (20.4\%). Consequently, the increase in the enrolments of Asian immigrant children seemingly posed significant challenges to early childhood education services when it comes to developing children's second language acquisition (Education Counts, 2013).

Acquiring a second language by young English language learners (ELLs) is indeed not simply a static outcome, but it also extends its status to an ongoing dynamic process in which each child develops along a unique continuum towards achieving English proficiency. Verbal interaction is viewed by Interactionist perspectives in the second language acquisition (SLA) field as being of crucial importance for second language learners. Furthermore, the development of cognition acts as the central theme of sociocultural theories. (Vygotsky, 1978).

Vygotsky (1978) argued, from a sociocultural point of view, that everything is learned on two levels. Initially, it is through interaction with others, followed by integration into the individual's mental structure:

Every function in the child's cultural development appears twice: first, on the social level, and later, on the individual level; first, between people (interpsychological) and then inside the child (intrapsychological). This applies equally to voluntary attention, to logical memory, and to the formation of concepts. All the higher functions originate as actual relationships between individuals (p. 57).

This concept of mental structure by Vygotsky is also called the "zone of proximal development" (ZPD). Vygotsky (1978) conceptualized the ZPD as a metaphoric space where children are able to reach a higher level of knowledge when assisted by a more knowledgeable person. Notably, this idea is formed on the basis of Vygotsky's view that the learner acquires concepts first through social interaction with others, and only then intrapersonally, where those concepts are thus internalised. Thus, the reason ZPD holds significant importance in second language acquisition is its ability to evaluate a second 
language learner's learning potential and the type of assistance that can be offered to encourage internalisation.

In relation to this, this study aimed to delve into the perspectives and practices of New Zealand early childhood teachers in promoting English acquisition among Asian immigrant ELLs. The central question of this study is:

What are New Zealand early child childhood teachers' practices in developing English acquisition among Asian immigrant ELLs?

\section{METHODOLOGY}

A qualitative case study was selected as the research design for this study. In comparison to other methods of data collection, qualitative researchers are responsive to the context, adaptable to circumstances, and involved in fieldwork where the researchers must physically go to the people, settings, and sites in order to observe behaviour in its natural setting (Merriam, 2009). As the primary instrument for data gathering and data analysis in this study, the researchers' objective was to explore New Zealand early childhood teachers' perspectives and practices in developing English acquisition among the ELLs.

\section{Sample}

This study employed purposive sampling as the sampling strategy. Creswell (2012) reasoned that the researcher must first determine what selection criteria are indispensable in choosing the sites or the people to be studied in order to begin purposive sampling. Thus, to find the best case to be studied, the researchers first needed to establish the criteria that would guide the case selection, and then choose several cases that meet those standards.

\section{Selection Criteria of Field Work Site}

Early childhood services and programmes which involved similar programmes are represented by the selection criteria for the sites to be studied. Indicatively, the more demographically similar the participants are the better a researcher's ability to understand the 'general' nature of the experience to be defined (Creswell, 2012). The criteria of the site were determined through a discussion 
with the head teachers, an analysis of their centre documentation, identification of the centre philosophies, and expected practices. As a result of the data from these, an overview of the philosophies and the programmes of each ECE centre were rendered. A crucial criterion was the linguistic diversity of the children who attended the ECE centres which was identified at this stage to ensure that a suitable sample number of child participants was available. Consequently, to provide the data, two ECE centres which met the selection criteria were selected. This action was also decided for the purpose of meeting the expectations about depth and quality, and additionally, for the completion of the study within the time frame of four months.

\section{Selection of Participating ECE Teachers}

Towards the goal of obtaining rich-cases, the selection of participating teachers in this study followed two criteria. Only teachers who had participated in early childhood teacher education programmes in New Zealand were selected because these programmes, while retaining roots in developmentalism, have focused on sociocultural and bicultural approaches.

Besides the qualifications, the second criterion for the choice of early childhood teachers at ECE services is that they have experienced working with ELLs between the ages of three and four years. This is because at these ages, the children's first language is already established. This study focused on early childhood from teachers' perspectives and practices in developing the English acquisition of ELLs. Patton (2002) proposed setting a minimum sample size "based on expected reasonable coverage of the phenomena given the purpose of the study" (p. 246). Consistent with the mindset to address the objective of this study, the number of participants chosen enabled us to focus on each participating case and to obtain rich information.

The two centres in the study were in New Zealand. The session routines for the first centre were five morning and afternoon sessions for children below three yearsold, and children between three and five yearsold. The second centre had five morning and afternoon sessions only for children between two and five yearsold. The programmes of both centres were founded upon Te Wharriki (Ministry of Education, 1996), the New Zealand early childhood curriculum. 
The philosophy of the first centre was to observe each child and extend their natural interest. Thus, the centre's objective was to guarantee that each child received individual attention to enhance positive development. Meanwhile, the philosophy of the second centre outlined that the programme supports the holistic development of each child. It also put an emphasis on reciprocal relationships with teachers and children. The centre was fully licensed for up to 37 over two year-old children. At the time of my observation, the children's enrolment was only 22 which indicated that the teacher/ child ratio was above the minimum standard that was 1:5 two to five's.

All teachers at both centres were qualified and obtained these qualifications in New Zealand tertiary institutions. Additionally, every teacher was registered except for one teacher from the first centre who was still in the first year of her teacher registration. Teacher registration in New Zealand gives evidence of their official membership of the teaching profession (New Zealand Teachers Council, 2014). Moreover, all teachers had experience working with a variety of children with home languages other than English including European, Māori, Asian, and Pasifika languages. Evidently, in the first centre, Jennifer and Heather were English- speaking teachers while Rosalind was a bilingual teacher who was very fluent in English but not from an Asian background. The background of these teachers reveal these details: Jennifer had taught in different settings of ECE for almost twenty years, Heather had been an ECE teacher for about four and a half years, while Rosalind had just started her career in teaching in the first centre for almost two years when this present study began.

Table 1

Profile of the teachers at the first centre.

\begin{tabular}{ll}
\hline Name of teacher & Language background \\
Rosalind & Bilingual \\
Heather & Monolingual (English) \\
Jennifer & Monolingual (English) \\
\hline
\end{tabular}


Moving on to the second centre, Angela singled out as the only English- speaking teacher while Razan, Ming and Akiko were bilingual teachers who had Asian backgrounds. Angela had been the Head teacher at the second centre for about four years. As for the other three teachers, Razan had been teaching in the second centre for about five years while Ming and Akiko had the experience of teaching there for about three years. Besides their experience as bilingual teachers, the centre also had children who had been raised in bilingual environments and attended English dominant educational settings.

\section{Table 2}

Profile of the teachers at the second centre.

\begin{tabular}{ll}
\hline Name of teacher & Language background \\
Angela & Monolingual (English) \\
Razan & Bilingual \\
Ming & Bilingual \\
Akiko & Bilingual \\
\hline
\end{tabular}

\section{Selection of Case Study Children}

ELL participants in the study from the first centre were Hyun-woo, Seo-yeon and Ji-Min who had, in common, the home language and had similar cultural backgrounds. Among the three of them, Hyunwoo was the oldest (he was four years and six months old at the time of observation), and had begun going to the first centre when he was about two years old. As soon as he had enrolled, he had attended an ECE programme for children below two yearsold before moving on to the programme for children aged between three and five yearsold. Due to his age he was enrolled in the first centre. Hyun-woo was familiar with the surrounding and the teachers, and had developed friendships with English- speaking peers as well as other ELLs at the centre. According to the teachers, Hyun-woo gradually became confident to communicate with the teachers and his peers in English. Hyun-woo's family had migrated to New Zealand six years ago but his mother, who was always seen sending and picking up Hyun-woo 
from the centre, was not as fluent in English and thus declined to be interviewed.

Seo-yeon first enrolled at the first centre just before he reached three yearsold, and attended the ECE programme for children below two yearsold only for a few months before moving on to the programme for children between three and fiveyear olds. When this study started, Seo-yeon was three years and three monthsold, and had only attended the above three years-old programme for about a few weeks. Seo-yeon, like Hyun-woo, was the eldest child in the family. Seo-yeon was perceived by the teachers as not being as proficient as Hyun-woo in English as a result of the difference in the time spent at the ECE centre. However, he had demonstrated considerably good efforts in acquiring English. The family background shows that Seoyeon's mother, Subin, had her final high school in New Zealand and his father was a businessman in New Zealand.

Table 3

Profile of the case study children at the first centre

\begin{tabular}{|c|c|c|c|c|}
\hline $\begin{array}{l}\text { Name of } \\
\text { child } \\
\text { and age }\end{array}$ & $\begin{array}{l}\text { Name of } \\
\text { parent } \\
\text { interviewed }\end{array}$ & $\begin{array}{l}\text { Level of } \\
\text { English } \\
\text { competence }\end{array}$ & $\begin{array}{l}\text { Other } \\
\text { languages } \\
\text { spoken }\end{array}$ & $\begin{array}{l}\text { Any adults } \\
\text { or other } \\
\text { children } \\
\text { who speak } \\
\text { the child's } \\
\text { first } \\
\text { language }\end{array}$ \\
\hline $\begin{array}{l}\text { Hyun-woo } \\
\text { (4 years and } \\
6 \text { months) }\end{array}$ & - & $\begin{array}{l}\text { Gaining } \\
\text { confidence to } \\
\text { use English } \\
\text { with friends } \\
\text { and teachers }\end{array}$ & Korean & $\begin{array}{l}\text { Children- } \\
\text { Yes } \\
\text { Adult } \\
\text {-teacher } \\
\text { reliever }\end{array}$ \\
\hline $\begin{array}{l}\text { Seo-yeon } \\
\text { (3 years and } \\
\text { 3months) }\end{array}$ & Subin & $\begin{array}{l}\text { Demonstrated } \\
\text { considerably } \\
\text { good efforts } \\
\text { in acquiring } \\
\text { English. }\end{array}$ & Korean & $\begin{array}{l}\text { Children- } \\
\text { Yes } \\
\text { Adult- } \\
\text { teacher } \\
\text { reliever }\end{array}$ \\
\hline $\begin{array}{l}\text { Ji-Min } \\
\text { ( } 3 \text { years and } \\
\text { two months) }\end{array}$ & Jeoung & $\begin{array}{l}\text { The initial } \\
\text { stage of } \\
\text { second } \\
\text { language } \\
\text { acquisition. }\end{array}$ & Korean & $\begin{array}{l}\text { Children- } \\
\text { Yes } \\
\text { Adult- } \\
\text { teacher } \\
\text { reliever }\end{array}$ \\
\hline
\end{tabular}


The third child participant of the first centre in the study was JiMin who was three years and two months old. He shared the same home language and a similar time frame of enrolment with Seo-yeon which made them good friends even before they both began the programme for children aged three to five yearsold. Among the three case study children at the first centre, the teachers suggested that Ji-Min was still at the initial stage of second language acquisition. Jeoung, Ji-Min's father, was worried about Ji-Min's first and second language acquisition as it was difficult for Ji-Min to express himself even in their first language in comparison to her brother and sister when they were at his age. The family had migrated to New Zealand about five years ago and Ji-Min's father was a postgraduate student at a university.

Table 4

Profile of the Case Study Children at the Second Centre

\begin{tabular}{|c|c|c|c|c|}
\hline $\begin{array}{l}\text { Name of } \\
\text { child } \\
\text { and age }\end{array}$ & $\begin{array}{l}\text { Name of } \\
\text { parent } \\
\text { interviewed }\end{array}$ & $\begin{array}{l}\text { Level of } \\
\text { English } \\
\text { competence }\end{array}$ & $\begin{array}{l}\text { Other } \\
\text { languages } \\
\text { spoken }\end{array}$ & $\begin{array}{l}\text { Any } \\
\text { adults } \\
\text { or other } \\
\text { children } \\
\text { who } \\
\text { speak the } \\
\text { child's } \\
\text { first } \\
\text { language }\end{array}$ \\
\hline $\begin{array}{l}\text { Masaru } \\
\text { (4 years and } \\
5 \text { months) }\end{array}$ & Zhi & $\begin{array}{l}\text { Used more } \\
\text { English in her } \\
\text { second year at } \\
\text { the centre. }\end{array}$ & Chinese & $\begin{array}{l}\text { Children- } \\
\text { Yes } \\
\text { Adult } \\
\text {-Yes (One } \\
\text { teacher) }\end{array}$ \\
\hline $\begin{array}{l}\text { Shin } \\
\text { ( } 3 \text { years and } \\
5 \text { months) }\end{array}$ & Suzu & $\begin{array}{l}\text { Began to } \\
\text { acquire } \\
\text { English as } \\
\text { a result of } \\
\text { playing with } \\
\text { his English } \\
\text { peers. }\end{array}$ & Japanese & $\begin{array}{l}\text { Children- } \\
\text { Yes } \\
\text { Adult- } \\
\text { Yes (One } \\
\text { teacher) }\end{array}$ \\
\hline $\begin{array}{l}\text { Ji Hun } \\
\text { (3 years } \\
\text { and two } \\
\text { months) }\end{array}$ & - & $\begin{array}{l}\text { Rarely used } \\
\text { English } \\
\text { verbally but } \\
\text { understood } \\
\text { English fairly } \\
\text { well. }\end{array}$ & Korean & $\begin{array}{l}\text { Children- } \\
\text { Yes } \\
\text { Adult- } \\
\text { Teacher } \\
\text { reliever. }\end{array}$ \\
\hline
\end{tabular}


For the purpose of seeing some progress in the quality of case studies, Yin (2009) has proposed some principles for any data gathering effort in case studies including the use of (a) multiple sources of evidence (evidence from two or more sources, converging on the same facts or findings), (b) a case study database (a formal assembly of evidence distinct from the final case study report) and (c) a chain of evidence (explicit links among the questions asked, the data collected, and the conclusions drawn). When gathering the data, semi-structured interviews with the teachers, interviews with the case study parents and field notes based on observations were done. Furthermore, a case study database was created where evidence significant to the study were gathered to link them to the research questions in the process of discussing the findings of the study and concluding it.

Unlike Hyun-woo, Seo-yeon, and Ji-Min who spoke the same home language, the three ELLs of the second centre, Masaru, Shin, and Ji Hun did not share the same home language. While they have Asian background, they still had to rely on nonverbal language, and limited English to interact among themselves, and other children.

Masaru was the only girl among the case study children. She had been enrolled at the second centre once she reached three years-old. At the time of my observation, she was four years and five months. Compared to the first year when she first enrolled, the teachers commented that Masaru was more verbal in her second year at the centre, and had a few good friends whom she always played together. Masaru was the middle child in her family and according to her mother; she was very quiet but gradually speaking more English with her siblings at home than using their home language. Masaru's family migrated to New Zealand about five years ago when her father was offered a job in New Zealand. Masaru's mother, Zhi, was willing to be interviewed although she was not able to speak in English very well, hence the interpreter during the interview.

Unlike Masaru who had been enrolled at the centre for almost two years (when this study began), Shin and Ji Hun had only been at the second centre for a few weeks when we began this study. Shin was three years and five months whereas Ji Hun was three years and two months at the time of my observation at the second centre. According to his teacher, while Shin was always seen to be playing 
with Ji Hun, Shin appeared to have been playing with more English speaking peers compared to Ji Hun due to their personality. Shin was described by the teachers as having a pleasant personality which encouraged other children to play with him. Shin's mother, Suzu, was an international student at a university and the family arrived in New Zealand about a year when we began the study at the centre. We were able to interview Suzu in this study and she was quite proficient in English.

Shin and Ji Hun were often seen playing together. However, Ji Hun appeared to be having difficulty in developing friendship with other children as they always did not invite him to play together or their play ended up in disagreement. Ji Hun rarely used English verbally but understood English fairly well. Ji Hun was the only child to his parents and the only grandchild to his grandparents from his mother's and father's side. Ji Hun was always sent and picked up by his grandparents from the centre. We did not get the consent to interview Ji Hun's parents for this study.

For the purpose of seeing some progress in the quality of case studies, Yin (2009) has proposed some principles for any data gathering effort in case studies including the use of (a) multiple sources of evidence (evidence from two or more sources, converging on the same facts or findings), (b) a case study database (a formal assembly of evidence distinct from the final case study report) and (c) a chain of evidence (explicit links among the questions asked, the data collected, and the conclusions drawn). When gathering the data, semi-structured interviews with the teachers, interviews with the case study parents and field notes based on observations were done. Furthermore, a case study database was created where evidence significant to the study were gathered to link them to the research questions in the process of discussing the findings of the study and concluding it.

\section{Data Gathering}

In order to get rich and detailed information about teachers' perspectives and practices to develop English acquisition among ELLs, two major methods of data gathering were employed for each case study. One of them was direct observations of early childhood teachers' practices in each ECE centre. The other was semi- 
structured interviews. These were accompanied by the reflective notes containing insights, understanding, questions and thoughts generated during the data gathering process. Besides the method, interviews were conducted with every early childhood teacher involved.

Table 5

Main Study Data Gathering for Each Teacher

\begin{tabular}{|c|c|c|c|}
\hline & $\begin{array}{c}\text { Pre-observation } \\
\text { Interview } \\
\text { (Teachers were } \\
\text { interviewed before } \\
\text { observation) }\end{array}$ & Observation & $\begin{array}{l}\text { Post-observation } \\
\text { Interview } \\
\text { (Teachers were } \\
\text { interviewed } \\
\text { after observation) }\end{array}$ \\
\hline Frequency & $\begin{array}{l}\text { Once } \\
\text { (Semi-structured) } \\
\text { Ongoing } \\
\text { (Unstructured) }\end{array}$ & $\begin{array}{l}4 / 5 \text { days a week } \\
\text { (for } 6 \text { weeks) }\end{array}$ & $\begin{array}{l}\text { Once } \\
\text { (Semi-structured) } \\
\text { Ongoing } \\
\text { (Unstructured) }\end{array}$ \\
\hline Duration & $\begin{array}{l}\text { An hour } \\
\text { (Semi- structured) }\end{array}$ & Full day & $\begin{array}{l}\text { One and a half } \\
\text { hours } \\
\text { (Semi- structured) }\end{array}$ \\
\hline
\end{tabular}

\section{RESULTS}

It was found that most of the ECE teachers used certain strategies to make their interactions more comprehensible to the ELLs. The scenario below is a reflection of some strategies employed by the teachers.

It was 'clean-up' time. Some of the children had gone back home while only a few were left at the centre before the teacher- in- charge held the last mat time session for the day. During this period, the teachers were usually busy cleaning up the centre. Thus, most of the children usually played by themselves. However, some children were seen helping the teachers, including Seo-yeon. The fact that there were not many children left towards the end of the day allowed me to always notice that Seo-yeon took the opportunity to seek 
more interactions with the teachers. Seo-yeon watched Rosalind wiping the table. He stood by the table, smiling to Rosalind. Rosalind got down on her knees and asked him, "Would you like to help?" Seo-yeon nodded his head and repeated the word 'help'. Rosalind told him to get the cloth hanging at the sink where the teachers usually washed painting brushes. Seo-yeon looked unsure. Rosalind showed him her cloth, "This is the cloth, and you can use it to wipe the table". As she talked to Seo-yeon, she demonstrated the action of wiping the table. Then she pointed towards the cloth hanging at the sink and said "The cloth is at the sink". Seo-yeon walked quickly towards the sink but he stopped halfway. He turned to Rosalind and shrugged his shoulders, indicating that he did not understand her instruction. Rosalind instructed him to walk further by counting the steps that Seo-yeon should take to reach the sink. "Walk straight [straightened her hand towards the sink] One step, two step and turn right [turning her body to the right from where she was standing]. Seoyeon grabbed the cloth and ran towards Rosalind. As both of them were wiping the table, Rosalind sang a "clean up" song, "We're going to t.i.d.y [ she spelled out the word tidy] tidy up, we're going to make this whole room clean."

Evidently, in this scenario, Rosalind was seen employing several strategies such as using gestures to ensure that Seo-yeon understood the instructions. First, she asked whether he wanted to help her, to confirm whether his behavior of standing at the corner of the table was to help. Following this, she showed him the cloth and said the word 'cloth' accompanied by the action of wiping the table. When she gave the instructions to Seo-yeon to go to the sink and take the cloth, she made use of simple words and body language to assist Seo-yeon to comprehend the message. Seo-yeon eventually accomplished what he wanted to do.

Other than the strategies used by Rosalind to ensure her instructions were clear to Seo-yeon, it was observed that Seo-yeon tended to initiate more interactions with the teachers when there were lesser children around, usually towards the end of the day session. The 
kind of interactions that were often observed were in the form of teachers giving instructions to him as shown by the 'clean up' scenario between Seo-yeon and Rosalind. The nature of interaction and the exact time when that interaction took place triggered further exploration by the researchers. Was it true that ELLs felt more comfortable in one-on-one interactions which helped them to understand interactions in English better? Was it more natural for the ELLs to prefer to be involved in interactions which oriented around instructions from adults? In many East and Southeast Asian cultures, Confucian ideals, which include respect for elders and showing self-control, have significant influence (Zhen, 2010). Most Asian parents tell their children to respect people in authority such as teachers (Zhen, 2010). In the example of the scenario between Seo-yeon and Rosalind, he was seen standing at a corner of the table, waiting to be asked by Rosalind whether he would like to help her. Perhaps this act of expecting her to ask him first is a sign of respect for her as a teacher that he would not interrupt what she was doing. In this scenario, Seo-yeon's behaviour could be interpreted as potentially leading to acculturation along integrative lines. $\mathrm{He}$ maintained his culture in which being respectful to the teacher is important, and waited to be given permission, like the other children attending the centre, to participate in activities as an integral part of the ECE community.

Rosalind commented on the scenario between her and Seo-yeon, and the way in which Seo-yeon approached her during 'clean up' time when there were fewer children:

Seo-yeon always goes home after 3 [o' clock]. Now that you asked, I notice that Seo-yeon always offers his help during clean up time. He and Ji-min always play together, so when Ji-min goes back at 3, he [Seo-yeon] always comes around. I thought he's being helpful, always likes to help, or maybe [he has] no good friends to play with or maybe [he has] nothing much to do. So, probably that's the reason and maybe [pause] that's how and when we always communicate with each other, not really engaging like I do with other children who speak English, but I guess that's fine; it takes time, he needs more English. 
Rosalind provided factors which could explain why Seo-yeon always looked for opportunities to initiate interactions with Rosalind such as his personality, not having good friends around, and there being nothing to do. She highlighted the fact that interactions between her and Seo-yeon were not "engaging" due to his English proficiency but she thought it was "fine". From Rosalind's view, "engaging" most likely refers to how she and the English -speaking children were able to talk about something in a more in-depth manner compared to how she interacted with the ELLs, which was usually brief and less verbally interactive. Engaging in interactions is one of the abilities entailed in sociocultural adaptation (Berry, 2006). Rosalind was implying that once Seo-yeon acquired English, the interactions would be more engaging.

However, there was a complexity in making the interactions more engaging among the ELLs. As evident in the 'clean up' scenario, Seo-yeon was possibly using the integration strategy during his acculturation process when he showed interest in interacting with Rosalind, and as a sign of respect he waited for Rosalind to ask him to help. However, Rosalind did not highlight the integration strategy used by Seo-yeon in her understanding of why the interactions between her and Seo-yeon were not engaging. In addition, Rosalind did not emphasise the maintenance of Asian culture which possibly led Seo-yeon to be respectful to the teacher by not interrupting her. She might have misinterpreted this as the interactions being less engaging due to limited English proficiency.

Nevertheless, Rosalind was observed to be accommodating Seoyeon's need for their interactions to be more comprehensible. She used a range of strategies to ensure her instructions were clear to Seo-yeon. Therefore, it was important to note that while the ELLs were using the acculturative strategy of integration in order to adapt themselves to the New Zealand ECE culture, the teachers might not be fully aware of the use of any acculturative strategy.

In summary, the scenario between Rosalind and Seo-yeon depicted two issues derived from the interactions which were representative of the two centres of the study.: Firstly, the acculturation strategies involved during the interactions were those of integration and mutual accommodation, and secondly, the need for the ELLs to acquire English to engage in interactions with the teachers as well as 
their English- speaking friends. The next section discusses the subtheme of cultural distance that revealed incongruence between the teachers' strategies and Asian cultural practices as the teachers and the ELLs interacted at the ECE centres.

\section{Cultural Distance}

A cultural distance is defined by the differences and similarities between the home culture and that of the host country (Berry, 2006). While the teachers provided examples of their strategies and were observed to provide strategies and modifications for the ELLs to ensure comprehensible interactions, there were incidents where sometimes the strategies were incongruent with the ELLs' culture. The clash could be due to cultural distance.

Both sociocultural adaptation and cultural distance are interrelated because they imply that the more different, or the greater culturally distant an immigrant's home and the host culture are, the more difficult their adaptation may be (Demes \& Geeraert, 2013). In terms of a social learning framework, individuals who are more culturally distant are likely to have fewer culturally appropriate skills for negotiating daily situations (Searle \& Ward, 1990). Among the differences were differences in language, differences in nonverbal communication, differences in rules and differences in values (Masgoret \& Ward, 2006). These differences may act as barriers to effective communication, positive social relations, and broader sociocultural adaptation (Masgoret \& Ward, 2006). For example, a smile can be misinterpreted by Western and Asian cultures. While a smile can be understood as happiness, in other cultures it may have very different meanings, including confusion and embarrassment (Kim \& Hinchey, 2013).

Sociocultural adaptation, therefore, requires understanding of relevant norms and cultures (Masgoret \& Ward, 2006). The present study has demonstrated that language can act as a cultural tool to understand Asian norms and cultures but there is a complexity due to cultural distance. Smith (2013) argued that language and culture are complexly interrelated as language is regarded as a cultural tool for individuals to make sense of themselves and their surroundings. From the observation of the researchers in this study, the existence of 
cultural distance that emerged from the differences in language and nonverbal communication is illustrated in the following scenario:

Alex was playing at the playground with his 'Action man' toy. He made sounds of the fighting man. Ji-min happened to pass by where Alex was playing. Ji-min wanted to see the toy, but Alex did not allow Ji-min to see his toy. He hid the toy behind his back. Ji-min tried a few times to see the toy but Alex was persistent and held the toy tightly. Ji-min did not utter even a word to indicate that he would just like to see the toy for a while. All he did was try to grab the toy from Alex. After a few unsuccessful attempts, he pushed Alex. Alex cried. He called out Jennifer's [teacher] name, as she was standing near them, and started crying. Jennifer asked Alex what had happened that caused him to cry and Alex explained the reason he was crying. Jennifer turned to Ji-min. She told Ji-min that she was not happy that Ji-min had pushed Alex. Jennifer used a lot of gestures, body language and facial expression when she was talking to Ji-min. However, Ji-min was looking down at the floor.

When Jennifer was asked to comment on the video recording that captured this scenario, she responded:

If it is a conflict resolution, I want them to see that I'm not happy. I mean, look at my face, I'm not happy, and if they are looking all over the place, they can't see that, they just hear the tone of your voice - they need to see your face. But, you know, with children that have English as a second language, I think it is really important that they look at your face and they look at your mouth when you're interacting with them.

In that brief duration of time when Jennifer was explaining to Ji-min that it was not acceptable to hit another child, he was observed to be looking at the ground and avoiding eye contact. He nodded a few times however, and he looked upset. When asked about the possible reasons for Ji-min's action, Jennifer responded: 
I think he couldn't really understand. That was why I needed him to see my facial expression, not only hear the tone of my voice. Ji-min seemed to have difficulty in understanding; maybe because of his English. He was new, anyway.

It was evident that Jennifer was making an effort to make Ji-min understand what she was saying to him due to Ji-min's limited English proficiency. Jennifer perceived that Ji-min was unable to understand her; so she claimed that she put in the effort of making the interactions more comprehensible through her facial expressions. Therefore, Jennifer was observed to accommodate the needs of Jimin, which was important during this period of acculturation to ensure comprehension.

However, it was important to note the incongruence between Jennifer's observed practices and Asian cultural practices. In the scenario where Jennifer was talking to Ji-min, he was observed to nod a few times and did not look directly into the eyes of his teacher. Nodding, generally in Western culture, means that the person who is listening understands or agrees, However, in Asian culture, nodding simply means that the person is listening and may not necessarily understand (Kim, 2007; Kim \& Hinchey, 2013). Also, Ji-min may have learned in Asian culture that it is disrespectful to look directly into the eyes of an authority figure like the teacher (Kim, 2007; Kim \& Hinchey, 2013). In contrast, Jennifer did not interpret Ji-min's response within the Asian cultural context and therefore, concluded that it was important for Ji-min to look at her face when she was talking to him.

In the context of sociocultural adaptation, Ji-min, being a new child at the centre, might have still been in the process of adapting himself to the New Zealand ECE culture. As a sign of being respectful to teachers in Asian culture, he had possibly learned that he had to nod to imply that he was listening to Jennifer and not to look directly at her when she was talking to him; thus, maintaining his Asian culture. In addition, Ji-min still had difficulties to adapt himself to the New Zealand ECE culture which advocated taking turns and asking permission before taking other children's toys. Jennifer, however, might not have understood Ji-min's reaction to the situation. She emphasised the importance of looking at her facial expression to 
make sure that Ji-min understood her message without relating his actions to his cultural practices. Therefore, the scenario between Jennifer and Ji-min demonstrated that there was incongruence between Jennifer's strategy and Ji-min's cultural practice.

The following discussion focused on the bilingual teachers' efforts to make interactions comprehensible to the ELLs. The bilingual teachers in the second centre appeared more aware of the incongruence between the teachers' strategies and the cultural practices than the English- speaking teachers. These bilingual teachers, Razan, Ming and Akiko, all had Asian cultural backgrounds, and were familiar with Asian cultural practices.

Akiko, a bilingual teacher in the second centre, highlighted that some practices were incongruent with Asian culture although they were widely acceptable among early childhood teachers, particularly English- speaking teachers. For example, in her interview, I asked Akiko to reflect on the cultural distance which the Asian immigrants ELLs were adapting themselves to socially and culturally. She reflected:

I understand it's not easy for the Asian children to behave as expected by other teachers. My background is the same [from Asian background]. Even as [an] adult, I learnt about so many things that do not fit with the Kiwi ${ }^{1}$ culture. Sometimes it can cause conflict because it is interpreted wrongly. With children who don't speak English, some teachers need to make sure the children understand, so they have to look at the face, or say something. But my upbringing said it's rude to look straight at the face. I usually explain to the Kiwi teachers ${ }^{1}$ here about this and other things, too just to let them understand why new [enrolled] children behave as such.

Jennifer and Akiko presented two contrasting views on some of the ECE teachers' practices. Jennifer, the English- speaking teacher, emphasised the need for the children to look at her face when she was speaking to make sure the child was paying attention, particularly

\footnotetext{
Kiwi culture refers to New Zealand culture.
} 
during conflict resolutions. However, Akiko, the bilingual teacher, highlighted that in Asian culture it is considered disrespectful to look directly at the teacher when the teacher is speaking to them. In this scenario, it is evident that limited cultural knowledge about how Asian children would react, particularly in the event of conflicts, caused some misunderstanding from someone such as Jennifer who comes from a Western cultural background.

Cultural distance can lead to acculturation stress (Berry, 2006). Stress resulting from cultural distance was observed to affect the interactions between Ji-min and Jennifer. Ji-min was always observed to have minimal interactions with the teachers and the Englishspeaking children. Since there were few interactions between Ji-min and the teachers and the English -speaking friends, Ji-min was seen to have fewer opportunities to acquire English compared to other ELLs at the centre. Ji-min's father, Jeoung, expressed his concerns:

He tried to speak as much as possible, but I don't know why this happened, but you know he's slow. He's got lots of things he wants to express, but he can't, so that's why he often gets frustrated, so that's why he yells and I think that also affects his behaviour. He wants to express lots of things, but like I say, he yells or he shows violent behaviour sometimes, because he can't communicate ideas properly. So that's our concern at the moment. But compared to the kids of his age, I think that he's still slow - so that's our biggest concern. But when it comes to English, I think he has more difficulty. I think language - communication is the key to his success in the centre. Again, he's got lots of things to express, but he can't, so that's why maybe it is hard for him to socialise.

Jeoung's concern was that Ji-min's limited English proficiency affected his behaviour and his socialisation. He believed it was also a reflection of the challenges that Ji-min faced in the process of adapting to the new, unfamiliar culture at the centre. From the researchers' observation, the challenges appeared most likely to stem from the cultural incongruences and Ji-min's limited proficiency in English, which affected the interaction between Ji-min and the teachers and his friends. 
When Jeoung was asked whether he had discussed his concern with Ji-min's teachers at the centre, he responded:

No... Not yet. I heard from the Plunket ${ }^{\square}$ nurse that I need kind of referrals from the centre, so I need to ask the teachers about my concern. Then they will look into this matter if they think it's necessary. But I don't know, I mean I'm not sure yet when.

It was apparent that Jeoung was hesitant to discuss his concerns regarding Ji-min's language even after the Plunket nurse recommended him to do so. While Asian cultures generally respect teachers and give the authority to teachers to teach their children (Kim \& Hinchey, 2013), in New Zealand ECE parents are encouraged to share their concerns about their children. Therefore, it was evident that cultural distance also occurred between the Asian parents and the New Zealand ECE teachers.

\section{DISCUSSION}

In conclusion, Ji-min was observed using separation strategies during his acculturation. While he was listening to the teacher, he was possibly maintaining his cultural practices by nodding his head as a sign of listening and being respectful to the teacher. However, he was still seen as struggling to adapt to the New Zealand ECE culture that encouraged children to take turns and ask permission before taking something from other children. His struggle, according to Jennifer and his father, was due to his limited English proficiency. Ji-min's father, Jeoung expressed his concern about Jimin's inability to express himself but he had not shared his concern, possibly because of his Asian cultural background which gives the authority to the teachers to teach their children. Moreover, Jeoung's possible reservation could be considered as a separation strategy; he maintained his cultural practices which give the authority to the teacher to deal with Ji-min's language ability.On the other hand, Jennifer was probably unaware of the Asian cultural way of respecting teachers by not looking directly at them when they were talking to the children. Hence, she emphasised that Ji-min should look at her when she was talking to him to aid his comprehension. Therefore, it was apparent that cultural distance affected the 
interactions particularly between Ji-min and Jennifer. Cultural incongruence was also highlighted by Akiko, the bilingual teacher, as she reflected on the practices in the second centre. She made the effort to explain to the New Zealand teachers about cultural distance so that the teachers would understand the behaviours of the ELLs which seemed to be incongruent with the ECE culture.

The cultural distance between the ELLs, the Asian parents and the teachers has been discussed in the context of sociocultural adaptation. Separation strategy was used by Ji-min and his father while they were adapting to the New Zealand ECE centre. This strategy reflected the cultural distance which was discussed in the scenario where Jennifer's effort was to make her interactions comprehensible and Jeoung's choice was not to approach Ji-min's teachers just yet, even though he was concerned about Ji-min's language ability which might lead to his behavioural and socioemotional issues. Therefore, in line with social learning perspectives, cultural distance, as discussed, is related to the use of language in acquiring social skills in the new unfamiliar culture.

While the teachers believed it was important to meet the needs of the ELLs and their families in the ECE setting, they seemed to overlook how these groups were affected during the adaptation process as far as English acquisition is concerned. During the acculturation process, the ELLs and their families had to adopt the basic values of the New Zealand ECE social environment. However, it was challenging for the ELLs to adapt to the new social environment with its different language, cultural rules and expectations. Sociocultural adaptation is a two-way process as it involves interactions between the immigrant and the host society (Monzo \& Rueda, 2006). From this perspective, the ELLs and their families, and the teachers need to understand how their interactions during the adaptation process could facilitate English acquisition. At the same time, the New Zealand ECE teachers must be prepared to adapt New Zealand ECE to better meet to the needs of the ELLs and their families.

However, the ELLs did not have the freedom to choose how they wanted to engage in interactions during their acculturation process. From a dominant group's perspective, the acculturation strategies can only be freely chosen and successfully pursued by non-dominant groups when the dominant society is open and inclusive in its 
orientation towards cultural diversity (Berry, 2006). Berry (2006) claimed that integration strategies can only be pursued in societies that are explicitly multicultural, in which certain psychological pre-conditions are established. These pre-conditions include "the widespread acceptance of the value to a society of cultural diversity", "a relatively low level of prejudice", "positive mutual attitudes among ethno- cultural groups" and "a sense of attachment to, or identification with the wider society by all individuals and groups" (p. 36). These pre-conditions are apparent in the New Zealand ECE curriculum as it advocates cultural diversity. Therefore, in theory, the teachers, as a dominant group in the acculturation process, should assist the ELLs to engage in interactions with the teachers and with their English- speaking friends so that they will be able to acquire English. This present study discovered a mismatch between the ideals of the curriculum and the reality of the practices in New Zealand ECE centres.

As the ELLs participated in joint activities with their friends and teachers within early childhood education (ECE) settings, they acquired new strategies and knowledge of the world and culture. From sociocultural perspectives, this interaction between the learners and the experts is widely regarded as occurring within the ZPD. Vygotsky (1978) suggested that the ZPD is the central activity space in which learning occurs, and the context in which the interaction occurs is crucial. These acquired strategies and knowledge were observed to assist the ELLs to adapt themselves socially and culturally. This perspective has been illustrated through the interactions between the ELLs and more knowledgeable others; for example, the teachers and their English- speaking peers.

While the two mainstream ECE centres provided a language-rich context for English acquisition, there were, however, complexities and challenges within the environment. These included the opportunities for the ELLs to participate in interactions, and the adaptation from the teachers, parents and the Asian immigrants. The opportunities for scaffolding through social interactions were often missed by the English- speaking peers and teachers. Walqui (2006) claimed that creating contexts for linguistic and other learning in the ZPD occurs in part through the scaffolding of social interaction. The importance of context for learning has been emphasised in sociocultural theories (Vygotsky, 1978) and the natural acquisition 
theory developed by Krashen and Terrell (Krashen, 1985; Krashen \& Terrell, 1983). Learning is thought to take place only when there is understanding (Haliza Harun, Norhana Abdullah, Nur Syuhada' Ab. Wahab \& Nurkhamimi Zainuddin, 2017), so the context provided by an early childhood centre should be relaxed and rich in comprehensible language (Krashen \& Terrell, 1983; Lake \& Pappamihiel, 2003). Therefore, in the context of this study, it is important that the teachers assist the ELLs in their understanding as they are making attempts to interact with the teachers and their peers.

The central significance of the findings is that through the exploration of New Zealand early childhood teachers' beliefs and practices, important insights have been offered in order to improve educational practices in early childhood settings for immigrant children in relation to English acquisition. While some of the teachers' beliefs and practices may have a facilitative effect on English acquisition, they may bring debilitative or harmful effects.

While this study is not conclusive in exploring the early childhood teachers' perspectives and practices in the New Zealand context, and the findings are not generalisable to other educational settings, it does offer helpful insights for teachers who work with children who are linguistically and culturally diverse in the complex terrain of contemporary early childhood education.

\section{ACKNOWLEDGEMENT}

This research received no specific grant from any funding agency in the public, commercial, or not-for profit sectors.

\section{REFERENCES}

Berry, J.W. (2006). Stress perspectives on acculturation. In D. L.Sam \& J. W. Berry (Eds.), The Cambridge handbook of acculturation psychology (pp. 43-57). New York, NY: Cambridge University Press. 
Creswell, J. W. (2012). Educational research: Planning, conducting, and evaluating quantitative and qualitative research. Boston, MA: Pearson.

Demes, K. A., \& Geeraert, N. (2013). Measures matter: Scales for adaptation, cultural distance, and acculturation orientation revisited. Journal of Cross-Cultural Psychology, 45(1), 91109.

Education Counts. (2013). Annual ECE summary report 2013. Retrieved from http://www.educationcounts.govt.nz/ statistics/ece2/annual-ece-summary-reports

Haliza Harun, Norhana Abdullah, Nur Syuhada' Ab. Wahab \& Nurkhamimi Zainuddin (2017). The use of metalanguage among second language learners to mediate L2 grammar learning. Malaysian Journal of Learning and Instruction, 14 (2), 85-114.

Kim, K. H. (2007). Exploring the interactions between Asian culture (Confucianism) and creativity. Journal of Creative Behaviour, 41(1), 28-53.

Kim, Y., \& Hinchey, P. H. (2013). Educating English language learners in an inclusive environment. New York, NY: Peter Lang.

Krashen, S. D. (1982). Principles and practice in second language acquisition. Oxford, UK: Pergamon Press.

Krashen, S. D., \& Terrell, T. D. (1983). The natural approach: Language acquisition in the classroom. London, UK: Prentice Hall.

Krashen, S. D. (1985). The input hypothesis: Issues and implications. London, UK: Longman.

Lake, V., \& Pappamihiel, N. E. (2003). Effective practices and principles to support English language learners in the early childhood classroom. Childhood Education, 70 (4), 200-203.

Masgoret, A.-M., \& Ward, C. (2006). The cultural learning approach to acculturation. In D.L. Sam \& J.W. Berry (Eds.), Cambridge handbook of acculturation psychology (pp. 5877). Cambridge, UK: Cambridge University Press.

Merriam, S. B. (2009). Qualitative research: A guide to design and implementation. San Francisco, CA: Jossey-Bass.

Ministry of Education. (1996). Te Whāriki: He Whāriki Matauranga mo nga Mokopuna o Aotereo. Early childhood curriculum. Wellington, New Zealand: Learning Media. 
Monzo, L., \& Rueda, R. (2006). A sociocultural perspective on acculturation: Latino immigrant families negotiating diverse discipline practices. Education and Urban Society, 38(2), 188-203.

New Zealand Teachers Council. (2014). Getting started: Registration. Retrieved from http://www.teacherscouncil. govt.nz/registering-as-a-teacher

Patton, M. Q. (2002). Qualitative research \& evaluation methods. Thousand Oaks, CA: SAGE

Searle, W., \& Ward, C. (1990). The prediction of psychological and sociocultural adjustment during cross-cultural transitions. International Journal of Intercultural Relations, 14, 449-464.

Walqui, A. (2006). Scaffolding instruction for English language learners: A conceptual framework. The International Journal of Bilingual Education and Bilingualism, 9(2), 159-180.

Vygosky. L. S. (1978). Mind in the society: The development of higher psychological process. Cambridge, MA: Harvard University Press.

Zhen, Z. (2010, May 3). Respecting teachers and cherishing virtue. The Epoch Times. Retrieved from http://www.theepochtimes. com/n2/china-news/respecting-teachers-cherishing-virtuechinese-34605.html 